\title{
A NOITE NÃO É UM ESPAÇO-TEMPO IGUALITÁRIO
}

\author{
Renata Sakurai \\ Universidade Estadual Paulista - UNESP, Mestrado em Geografia, Presidente Prudente, SP. E-mail: \\ hair renata@hotmail.com. Agência de fomento FAPESP
}

\section{RESUMO}

Situado no âmbito do Projeto Temático Fapesp, "Lógicas Econômicas e Práticas Espaciais Contemporâneas: cidades médias e consumo" ${ }^{1}$, nosso artigo busca contribuir com os estudos que envolve as relações entre novas lógicas econômicas e redefinição de práticas espaciais de consumo, a partir da abordagem da dinâmica da vida noturna, da cidade de São José do Rio Preto/SP. Nesse bojo, o trabalho articula a conquista da noite com a temática do consumo de lazer e diversão ainda recente no âmbito das preocupações geográficas, mais especificamente buscamos analisar as estratégias de seletividade por parte dos agente econômicos que ofertam a vida noturna na cidade.

Palavras Chave: Noite; Lazer e diversão noturnos, São José do Rio Preto/SP.

\section{NIGHT IS NOT AN SPACE-TIME EQUALITY}

\begin{abstract}
Located in the Thematic Project FAPESP, "Economic Logic and Spatial Practices: middle size cities and consumption, this paper to contribute to the studies that involve the relations between new economic logic and the redefinition of spatial consumption practices, dynamic nightlife the city of São José do Rio Preto/SP. This work articulates the conquest of the night with the theme of leisure consumption and fun still recent in the scope of geographic, more specifically, to analyze the strategies of selectivity on the part of the economic agents that offer the nightlife in the city.
\end{abstract}

Keywords: Nigth; Nightlife; São José do Rio Preto/SP.

\footnotetext{
${ }^{1}$ Projeto de pesquisa conduzido pelo Grupo de Pesquisa Produção do Espaço e Redefinições Regionais - GAsPERR, com financiamento da Fundação de Amparo à Pesquisa do Estado de São Paulo - FAPESP, processo no: 2011/20155-3 


\section{INTRODUÇÃO}

A primeira cidade que passou a ter iluminação elétrica pública foi Birgminghan, no Reino Unido, Alves (2004), sob este ponto, Santos e Moreira (2008) argumentam que a luz artificial proporcionou ao sujeito uma emancipação dos ritmos naturais que a natureza impunha sobre a ação do sujeito. Deste modo, os ciclos impostos pela natureza, mais precisamente, o tempo da noite e o dia, não demarcam uma problemática na vida do sujeito, pois, a sociedade possui técnicas, que são capazes de atenuar esta transição do dia para a noite, como o fogo, carvão, gás e atualmente a energia elétrica. Para Turra Neto (2016), a noite nunca foi um tempo de absoluto despovoamento de práticas sociais, da sociabilidade, contudo, o fato que mais demarcou a difusão de atividades noturnas foi a invenção da lâmpada elétrica.

Anteriormente os espaços na cidade, após o pôr do sol, só eram ocupados quando a luz natural do luar permitia, ou então, sob outro tipo de iluminação, como as fogueiras ou tochas, restringindo o tempo de lazer e sociabilidade urbana em sua maior parte no espaço privado da casa. Deste modo, a luz artificial proporcionou para o sujeito a conquista da noite, fez com que a sociabilidade antes restrita apenas à esfera privada, ou a alguns poucos momentos, segundo um calendário festivo, ocupasse outros espaços e tempos.

Sob este ponto, podemos afirmar que foi graças à luz artificial, em maior notoriedade quando a fonte energética passa a ser a eletricidade, que os significados da noite nas cidades se transformou (Santos e Moreira, 2008). Teresa Alves (2008, p.3-4), reafirma que com a introdução desta matriz energética, o cotidiano dos sujeitos deixou de ser regulamentado "pela sucessão do dia e da noite e foi-se ajustando mais à necessidade da sequência das tarefas e das funções". A luz artificial fez com que a circulação dos sujeitos se intensificasse durante a noite, dando novos significados aos espaços. A noite não é mais um tempo voltado sobretudo ao descanso, abre a possibilidade para o trabalho, descanso e lazer. Deste modo, com a eletricidade temos alterações nos modos de vida dos sujeitos.

A princípio, a iluminação tinha sua função relacionada apenas à segurança nas cidades. Contudo, a luz passa a estar relacionada ao lazer e foi na Exposição Mundial de Paris, em 1900, que a luz teve papel fundamental para o lazer, usada para a iluminação externa de ambientes (ALVES, 2008). Nesta perspectiva Góis (2015), Turra Neto (2016) ao falarem da vida noturna na cidade, argumentam que os espaços de lazer e diversão noturnos, ocorrem em determinados espaços da cidade e negam outros, tais locais tendem a formar centros de vida noturna. Assim Turra Neto (2016, p.757) inspirado em Challéat ${ }^{2}$ (2011), argumentou que a “iluminação urbana tem uma participação crescente na fabricação da própria cidade e da vida urbana, não apenas na criação de uma atmosfera, mas na valorização diferencial dos locais da cidade."

A noite, para Margulis (1997), especialmente para os sujeitos que consomem o lazer e diversão noturnos, não é uma noite, sobretudo, da escuridão. É o oposto da noite regida pela natureza, em que a luz advém das estrelas e do luar. A noite urbana é iluminada e oferece uma misticidade dos lugares onde há sombras, que podem ser vistos como locais de maior privacidade. Nesta perspectiva, nosso objetivo consiste em estudar a dinâmica do lazer e diversão noturnos em São José do Rio Preto/SP, e como os empresários da noite utilizam a iluminação como forma de barreiras simbólicas ao acesso de seus estabelecimentos, outras estratégias também serão abordadas, como a estratégia de seletividade via vestimentas e valor de portaria dos seus estabelecimentos que negam as diferenças dos sujeitos e criam espaços homogêneos do ponto de vista social e econômico

A metodologia utilizada foi a observação participante, pois ao colocar o sujeito em nossa análise, o geógrafo se vê obrigado a compartilhar metodologias de outras ciências. Deste modo, partimos da premissa de Geertz $(1978$, p.8), segundo o qual o homem é visto como "um animal

\footnotetext{
${ }^{2}$ Para mais informações: CHALLEAT, S. La nuit, une nouvelle question pour la geographie. BAGF, p. 1-12, $2011-2$. 
amarrado a teias de significado que ele mesmo teceu" e caberia à ciência interpretá-la. E, neste caso, utilizamos da Antropologia a metodologia da observação participante. Desta forma, podemos compreender as novas abordagens culturais que são travadas pelos sujeitos no consumo e oferta de lazer e diversão noturnos, numa tentativa de ler e descrever os atos e gestos dos sujeitos estudados, conseguindo interpretar os seus gestos que transmitem valiosas informações, quando decifrados os seus signos. Assim, participar do universo simbólico de deles é compreender como estes códigos e signos são transmitidos e compreendidos. Deste modo, a observação participante é um meio pelo qual o pesquisador pode interagir de forma menos hostil ao grupo. Esta metodologia pode ser entendida como:

[...] um processo pelo qual mantém-se a presença do observador numa situação social com a finalidade de realizar uma investigação científica. O observador está em relação face-a-face com os observados e, ao participar da vida deles no seu cenário natural, colhe dados. Assim o observador é parte do contexto sob observação, ao mesmo tempo modificando e sendo modificado por este contexto. (SCHWARTZ e SCHWARTZ apud CICOUREL, A, 1980, p 89).

\section{RESULTADOS E DISCUSSÕES}

Com a difusão da energia elétrica, a iluminação se tornou preocupação dos agentes econômicos do lazer e diversão noturnos, uma vez que valorizam os seus espaços sob a ótica artística da iluminação. São pequenos detalhes, como o impacto visual, que contribuem para uma seletividade dos sujeitos e dos espaços, pois, a partir desta ações, criam-se barreiras simbólicas, além das econômicas a seus estabelecimentos. A figura 1 revela a preocupação com a iluminação dos estabelecimentos de lazer e diversão noturno.

Figura 1. Fachada Luminosa do Chess Pub, São José do Rio Preto/SP

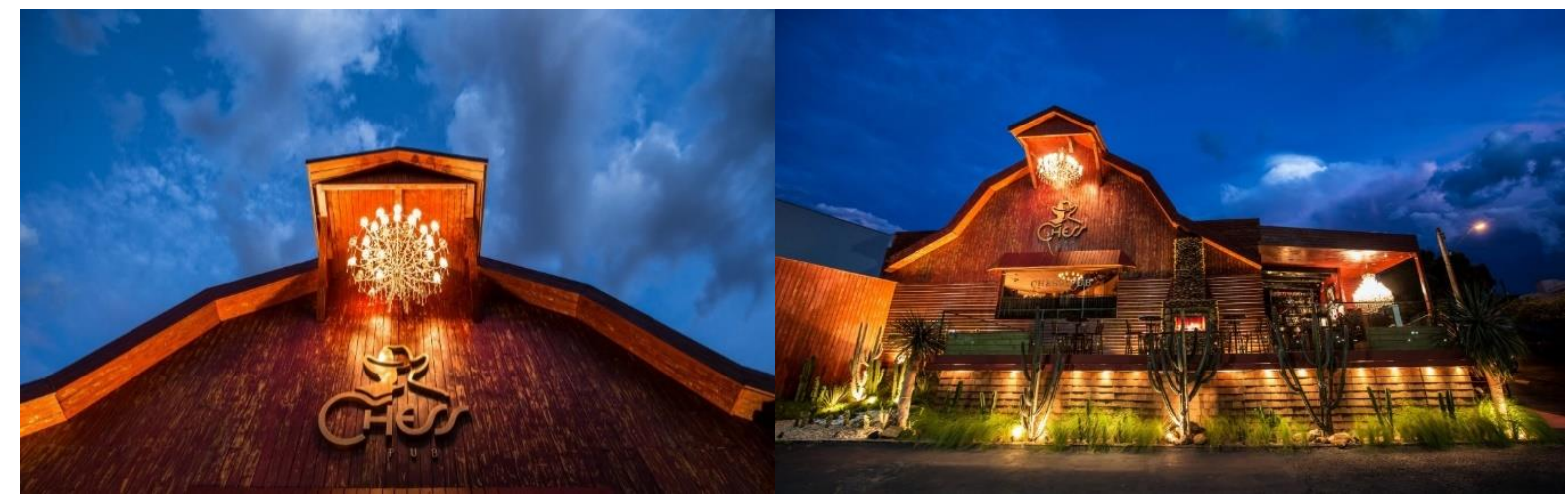

Fonte: Site $<<$ http://www.chesspub.com.br/riopreto/sobre/>>. Acesso em Janeiro de 2017

A iluminação introduziu um novo elemento na estrutura nas cidades, a luz artificial estabeleceu uma hierarquia entre os lugares (SANTOS \& MOREIRA, 2008). Conforme observado na imagem acima, a luz é um recurso utilizado pelo agente econômico que, combinada à arquitetura, também compõe o rol de impactos visuais que alguns tipos de estabelecimentos de lazer e diversão noturnos acionam. Com isto, buscam afirmação como locais mais importantes na diversificada paisagem noturna da cidade (GÓIS 2015). Alves (2008), na mesma linha de raciocínio, argumenta que a iluminação artificial magnifica os espaços urbano, os formatos, e permite ao sujeito uma percepção plural do estabelecimento e dos acontecimentos que lá ocorrem. A luz pode contribuir para novos papéis no lazer e diversão noturnos, sendo capaz de criar laços afetivos de identidade pertencimento ou de não pertencimento aos lugares. 
A noite no contexto de lazer e diversão noturnos passa a ser entendida como uma promessa de festa, uma festa que avança a madrugada e, às vezes, tem o seu final no amanhecer do outro dia. Os sujeitos que consomem a vida noturna são basicamente jovens, é o tempo oposto ao dos adultos.

La noche aparece para los jóvenes como ilusión libertadora. La noche comienza cada vez más tarde. Se procura el máximo distanciamento com el tiempo diurno. Com el tiempo de todos, de los adultos, el tiempo "regulamentado"; la mayor separación entre el tiempo de trabajo y el tiempo del ócio. Este tiempo distanciado, conquistado a contracorrente de las costumbres y los hábitos, este tiempo especial, parece propicio para la fiesta. (MARGULIS, 1997, p.15).

No entanto, a noite ao se manifestar como tempo para a festa, estamos querendo dizer que é o tempo para que os sujeitos gozem de um "direito a uma idade plena de lazer, na exata dimensão e proporção de sua constituição física acabada e de sua visão de mundo a acabar e a moldar" (CAMARGO, 1992, p.57). A noite, entendida como um momento libertador, relaciona-se com as cargas de prazer que o lazer oferece para o sujeito.

A noite, ou seja, o lazer e a diversão noturnos não são propostas espontâneas, seguem um modelo comercial, que são modelos formatados e difundidos para o consumo. Com isso, utilizam de um tempo e um espaço próprio para sua sustentação, quebrando com o tempo e espaço determinado pela funcionalidade do dia, "ruptura com el tiempo y el espacio habitual. La fantasía, la irrealidad, el distanciamiento de lo cotidiano, se incrementam com recursos y artificios en el interior de los locales: decoración, iluminación, centellleo de luces, intensidad de la música." (MARGULIS, 1997, p.16). Nesta perspectiva, a noite simula uma festa, os seus interiores também contribuem para o simulacro e sensação de liberdade do real (figura 2).

Figura 2. Decoração e lluminação do interior dos bares

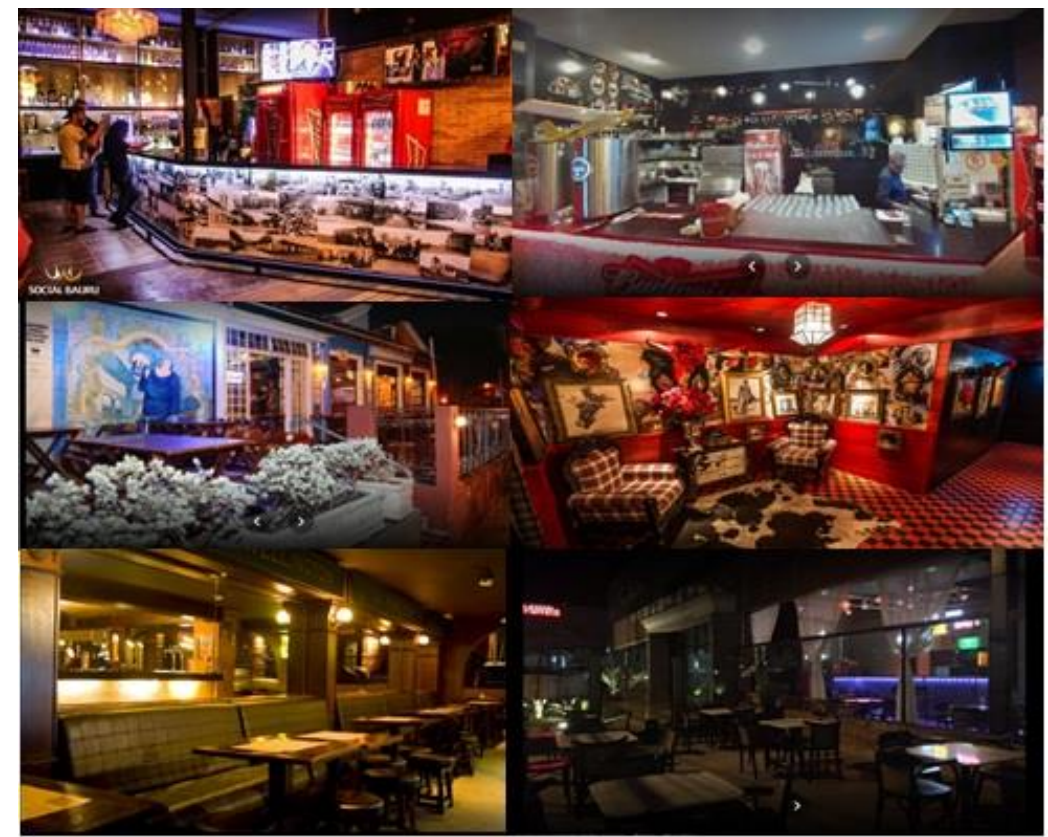

Fonte: Facebook, Instagran, Social Bauru, 2016 
A oferta de lazer e diversão noturnos em São José do Rio Preto/SP segue o modelo comercial vendido universalmente:

[...] es la fiesta organizada, controlada por otros. Es simulacro de fiesta, en el que deliberadamente se instalan ingredientes de transgresión de lo cotidiano: la luz, el espacio, el tiempo, la música cuyo volumen la transforma em algo casi corpóreo [...] se convierte, por mediación de la violência ejercida al elevar desmensuradamente su volumen, en um ingrediente más del espacio, en un cuerpo casi sólido. Es simulacro de fiesta y es relativa la liberación; los poderes están presentes de modo notorio y opressivo. Los jóvenes no ofician su propia fiesta, no crean sus regras, no regulan su espacio; son actores en un teatro ajeno, consumidores dentro de um género que les oferece alguma possibilidad de elección, pero siempre aceptando reglas que no han creado, rígidas formas de exclusión o admisión, códigos a los que hay que someterse, adaptarse, mimetizarse, para ser elegible "tener éxito", ser miembro. (MARGULIS, 1997, p.16-17).

Por traz da atuação dos agentes econômicos de lazer e diversão noturnos, promovem e revelam novas formas de dominação e de legitimação da distinção e exclusividade. A oferta de lazer e diversão noturnos se impõe pela noite na cidade e promove a possibilidade de um tempo de festa, diversão, quebra de rotina, encontro de pares, sociabilidade, romances, sexo, drogas mas tudo sobre o controle de seguranças e segundo as regras dos estabelecimentos. Além disso, no trabalho de campo, estratégias foram identificadas para elitizar os espaços em que o lazer e diversão noturnos acontecem. Por exemplo, em um final de semana, estávamos em um estabelecimento observando o ritual de entrada dos sujeitos, até que um deles iniciou uma conversa. O sujeito contou que de início, tinha planejado ir para outro estabelecimento, mas os seguranças não o deixaram ele entrar, pois estava usando uma bermuda e uma camiseta e sua vestimenta não era apropriada para frequentar o lugar, tendo que redefinir onde ir.

Nesta perspectiva, a noite que se apresenta na cidade não é uma noite neutra e acessível para todos os sujeitos. Os estabelecimentos, em sua maioria, acionam algumas estratégias para selecionar os sujeitos, como no exemplo acima citado, mas também os selecionam no tempo e no espaço. No tempo, via a atuação de cobrança de portaria para entrar e promoções de bebidas. Na figura 3, observa-se que, conforme os dias da semana vão passando, o preço da portaria é aumentado, como estratégia para selecionar o público.

Figura 3. Seletividade durante a semana

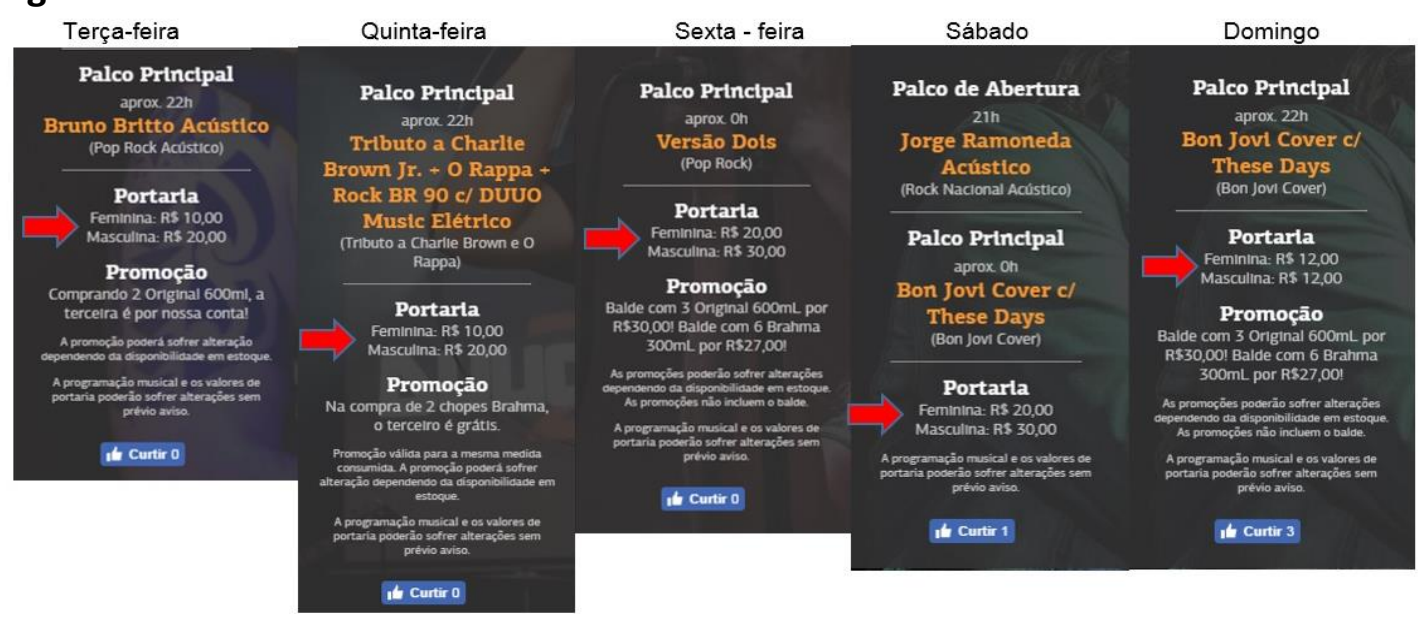

Fonte: <<www.viladionisio.com.br >>, acesso em junho de 2016 
Já a seletividade no espaço se dá a partir da subdivisão interna do ambiente. Parte do espaço é separado com algumas "barreiras" conforme mostra a figura 4, a presença de espaços cercados por estruturas de ferros e cordas restringe o acesso.

Figura 4. Dinâmica da cultura de distinção, exclusividade e hierarquias, via camarotes

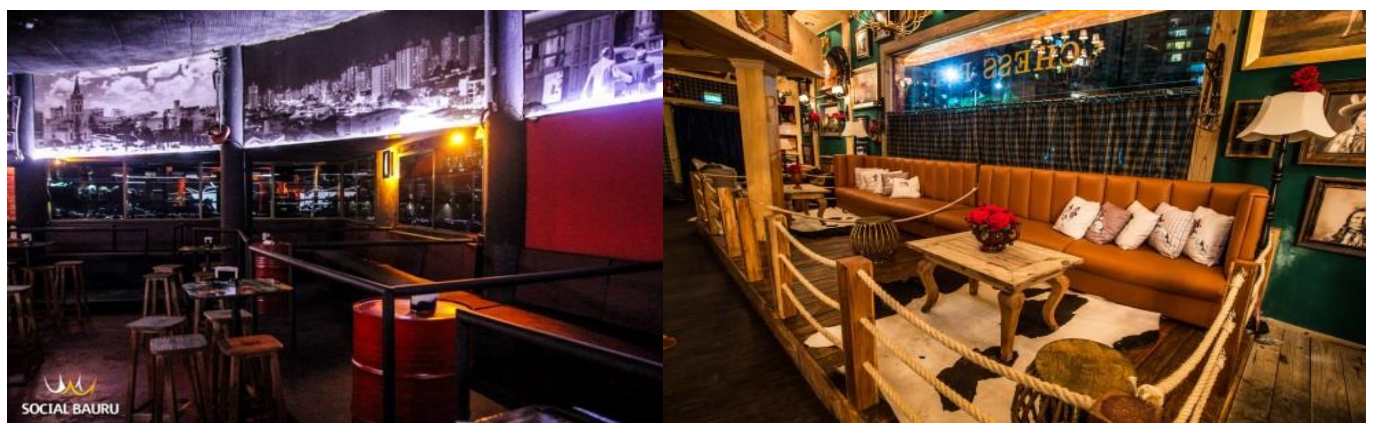

Fonte: Social Bauru \& <<http://www.chesspub.com.br/riopreto/>>, acesso 2016

\section{CONCLUSÃO}

Os empresários da noite almejam e promovem a ampliação e a conquista de novos públicos, ao conceder valores de portaria acessíveis, promoções de bebidas, mas eles também promovem a restrição, somente alguns sujeitos têm o acesso a determinadas áreas, criam espaços baseados no status, na diferença. O espaço interno do estabelecimento é gerido segundo os incluídos e os excluídos. Sob este aspecto, concordamos com Margulis (1997, p.17), quando afirma que "la cultura de la noche es etnocêntrica, classista y, hasta poderíamos decir, racista."

Os agentes econômicos de lazer e diversão noturnos apresentam uma oferta estandardizada, com signos de modernidade e de distinção, imposta ao público. Nesta perspectiva, o conteúdo da noite apresentada para os sujeitos, segue a lógica mercantil, é uma noite excludente, homogênea e dominatória, que reproduz e legitimam as formas de diferenciação e exclusão.

\section{REFERÊNCIAS}

ALVES, T. Geografias da noite. Fazer Geografia através da luz. In: Congresso da Associação Portuguesa de Geógrafos. Anais do V Congresso da Associação Portuguesa de Geógrafos. Lisboa: Universidade de Lisboa. 2004

CAMARGO, L. O. de L. O que é lazer. São Paulo: Editora Brasiliense, 1992.

GEERTZ, C. Uma descrição densa: por uma teoria interpretativa da cultura. In: $A$ interpretação das culturas. Rio de Janeiro: LTC Editora, 1989a.

CICOUREL, A. Teoria e método em pesquisa de campo. In: NUNES, E. de O. (org). Desvendando máscaras sociais. Rio de Janeiro: Francisco Alves, 1980. p. 87-121.

GÓIS, M. P. F. de. Paisagens noturnas cariocas: formas e práticas da noite na cidade do Rio de Janeiro. 332 fl. 2015. Tese (Programa de Pós-graduação em Geografia). Universidade Federal do Rio de Janeiro. Rio de Janeiro, 2015.

MARGULIS, M. La cultura de la noche: la vida nocturna de los jóvenes em Buenos Aires. Buenos Aires: Biblos, 1997. 
SANTOS, N. P. dos; MOREIRA, C. O. O lazer e a noite. Imagens de uma cidade universitária: Coimbra. In SANTOS, Norberto Pinto dos; GAMA, António, Org. Lazer: da libertação do tempo à conquista das práticas. Imprensa da Universidade de Coimbra: Coimbra, 2008. p. 247-271.

TURRA NETO, N. Vida noturna, a construção de um objeto de estudo para a Geografia. V Seminário Nacional Sobre Múltiplas Territorialidades E IV Seminário Internacional Sobre Microterritorialidades Nas Cidades. Anais...Ponta Grossa, 2016. p.756-772. 